\title{
Subsídios para esclarecimento do conceito de livro paradidático
}

\author{
Subsidies to clarify the concept of paradidatic book
}

\begin{abstract}
Bernadete Santos Campello
Doutora em Ciência da Informação pela Universidade Federal de Minas Gerais - UFMG. Professora titular aposentada da Escola de Ciência da Informação da Universidade Federal de Minas Gerais UFMG.

E-mail: $\underline{\text { bscampello@gmail.com }}$

Eduardo Valadares da Silva Doutorando em Ciência da Informação pela Universidade Federal de Minas Gerais - UFMG. Professor Assistente na Universidade Federal de Minas Geais. Membro do Grupo de Estudos em Biblioteca Escolar - UFMG.

E-mail: edu_valadares@yahoo.com.br
\end{abstract}

\begin{abstract}
Resumo
O termo livro paradidático, criado no âmbito da indústria editorial brasileira, se confunde com outros, como livro informativo e obra complementar. O presente trabalho tem como objetivo compreender o conceito, buscando esclarecer controvérsias que cercam sua identidade. Metodologicamente, este estudo se deu em dois momentos: no primeiro analisou-se o uso do termo pelo mercado editorial, utilizando-se uma amostra de sites de dezessete editoras. No segundo, foi realizado um estudo bibliográfico que permitiu entender como os textos acadêmicos e alguns documentos de política pública percebem o termo. Os resultados mostraram que fatores comerciais e pedagógicos contribuíram para a produção de paradidáticos, e também que existe uma imprecisão no uso do termo tanto pelas editoras como nos textos acadêmicos. No meio editorial e nos documentos de políticas públicas, o termo vem perdendo força, embora a prática de complementação do livro didático por professores continue sendo objeto de estudos no meio acadêmico, que ainda adota o termo paradidático.
\end{abstract}

Palavras-chave: Livro paradidático. Biblioteca escolar. Mercado editorial.

\begin{abstract}
The term "paradidatic book", created in the context of the Brazilian publishing industry, is imprecise and gets confused with others, like informative book and complementary material. The publishers themselves and academic texts on the subject do not contribute to its clarification. The present work aims to understand the concept, seeking to clarify controversies surrounding its identity. Methodologically, the study occurred in two moments: in the first one the use of the term by the publishing sector was analyzed, using a sample of websites of seventeen publishers. In the second, a bibliographic study was carried out that allowed to understand how academic texts and documents of public policy perceive the term. The findings demonstrate that commercial and pedagogical factors contributed to the production of paradidatic books, and confirmed the imprecision of the use of the term both by publishers and in academic texts. In the editorial context and in the public policy documents, the term has been losing strength, although the practice of supplementing the textbook by teachers continues to be studied in the academic world, which still adopts the term paradidatic.
\end{abstract}

Keywords: Paradidatic book. School library. Publishing market.

Bibl. Esc. em R., Ribeirão Preto, v. 6, n. 1, p. 64-80, 2018.

DOI: 10.11606/issn.2238-5894.berev.2018.143430 


\section{Introdução}

O estudo de fontes de informação, compreendidas como quaisquer recursos que respondam a uma necessidade de informação dos usuários da biblioteca, tem estado presente nos currículos de formação de bibliotecários desde que tiveram início os cursos profissionais de Biblioteconomia (SILVEIRA, 2007). Diferentes dimensões das práticas biblioteconômicas exigem o conhecimento da natureza, das características, da função e especialmente do uso e da avaliação das fontes, dentre outros aspectos. Esse conhecimento é imprescindível, por exemplo, na seleção e aquisição do acervo, no trabalho de referência, no desenvolvimento da competência informacional dos usuários e inclusive no processamento técnico no que diz respeito ao tratamento temático e descritivo das obras.

Há uma vasta literatura sobre fontes de informação que auxilia no processo de formação do bibliotecário e o ajuda a entender as diferentes formas textuais que compõem o universo informacional e que devem compor a coleção da biblioteca (CAMPELLO, CALDEIRA, MACEDO, 1998; CAMPELLO, CALDEIRA, 2005; CAMPELLO, CENDÒN, KREMER, 2000; CUNHA, 2010; TOMAEL, ALCARÁ, 2016).

Neste trabalho, o objetivo é compreender o conceito de uma fonte de informação presente especialmente em bibliotecas escolares: o livro paradidático. Portanto, busca-se esclarecer controvérsias que cercam sua identidade, já que mesmo no âmbito acadêmico há imprecisão no uso do termo, conforme demonstra Thomson (2016).

\footnotetext{
Mas, afinal, o que são livros paradidáticos? Há alguns anos esse conceito poderia ser definido com maior facilidade, pois, nos próprios catálogos das editoras, encontravase uma espécie de 'rótulo' definindo obras como paradidáticas ou não. Contudo, na atualidade, a ampliação do mercado literário causou uma certa 'diluição' dessas definições conceituais quanto à tipologia da obra (THOMSON, 2016, p. 28).
}

Sabe-se que as principais qualidades esperadas de um livro paradidático são que contenha informações corretas e que tenha capacidade de incentivar a aprendizagem, tornando mais interessante o estudo de um tema sem que o mesmo possa ser considerado um texto “didatizado" como normalmente se encontra nos livros didáticos. A sinopse de divulgação do livro Tem penas ou tem pelos? (observe o título curioso) da Editora Positivo exemplifica a noção de paradidático:

Uma criança está feliz porque vai chegar seu animal. Mas que animal será esse? Será que tem asas e voa ou tem escamas e vive na água? Será um jabuti? Quem sabe um animal que mama ao nascer? Com perguntas e respostas que tratam das características dos animais vertebrados, o livro instiga o leitor iniciante a reconhecer os mamíferos, 
as aves, os peixes, os répteis e os anfíbios. Ao longo do livro o animal imaginário vai se transformando conforme são descartadas as características que não possui. Um livro diferente sobre os animais que trata, de forma lúdica, temas das ciências naturais, como classificação, morfologia, reprodução e ecologia (EDITORA POSITIVO, [201?].).

Mas não seriam essas as qualidades que qualquer produção destinada à educação de crianças, adolescente, jovens e adultos ${ }^{1}$ deveria possuir? Então por que criar um termo específico para esse tipo de livro? Essas questões direcionaram o presente estudo, que pretende, especificamente, compreender o contexto de surgimento do livro paradidático, o crescimento do mercado de paradidáticos e os diferentes aspectos de sua produção, buscando elementos para esclarecer o conceito. Pretende-se, assim, oferecer ao bibliotecário embasamento para suas práticas, a fim de que ele possa exercê-las de forma crítica.

A metodologia utilizada foi o estudo bibliográfico a partir de um levantamento, usandose o termo "paradidático", nas seguintes fontes: Base de Dados em Ciência da InformaçãoBRAPCI (em todos os campos), Google Acadêmico (em páginas em português), Portal Capes (periódicos revisados por pares), Scielo (pesquisa por artigo, usando o formulário básico, em todos os índices), PERI/UFMG (pesquisa simples) e Literatura Brasileira em Biblioteca Escolar - LIBES (por título, palavra-chave e resumo) ${ }^{2}$. As referências dos textos e dos materiais utilizados são apresentadas em apêndice ao final do artigo.

O Google Acadêmico foi a fonte que forneceu o maior número de referências (12300 resultados), sendo quantitativamente limitados os resultados das outras fontes ${ }^{3}$ (incluir nota de rodapé:). Os critérios basearam-se nas seguintes características dos textos: textos acadêmicos, tais como, artigos de periódicos acadêmicos, trabalhos de eventos, teses e dissertações, em PDF, selecionando-se material que continha informações que possibilitassem atingir os objetivos do presente estudo, isto é, que permitissem compreender o contexto de surgimento do livro paradidático, suas características e aspectos de sua produção, enfim, que oferecessem elementos para esclarecer o conceito.

Além disso, para entender como as editoras utilizam o termo paradidático foi feito um levantamento em sites de dezessete editoras, listadas no Quadro 1. Essa amostra foi composta

\footnotetext{
${ }^{1}$ Consideramos aqui os adultos que se encontram no processo de escolarização na modalidade de Educação de Jovens e Adultos - EJA.

${ }^{2}$ Brapci (http://www.brapci.ufpr.br/brapci/), Google Acadêmico (https://scholar.google.com.br/), Portal Capes (http://www.periodicos.capes.gov.br/), Scielo (http://www.scielo.br/?lng=pt), PERI/UFMG (http://bases.eci.ufmg.br/peri.htm) e LIBES (http://libes.eci.ufmg.br/).

3 BRAPCI - 3 referências; Portal Capes - 10 referências; Scielo - 2 referências; PERI/UFMG - 0 referências; LIBES - 0 referências.
} 
pelas editoras que fazem parte da Associação Brasileira de Editores de Livros Escolares Abrelivros $^{4}$. A pesquisa foi feita no período de 11 a 19 de setembro de 2017, utilizando-se inicialmente a caixa de busca do site (quando disponível), usando-se o termo "paradidático". Em seguida, foi feita uma varredura em todo o site para verificar se o termo era usado nos diferentes links existentes.

\section{O surgimento do termo paradidático}

O termo paradidático surgiu no âmbito da indústria editorial no Brasil e é tipicamente brasileiro. Foi cunhado por Anderson Fernandes Dias, diretor-presidente da Editora Ática, no final da década de 1970, época na qual as editoras do país expandiam seu mercado com a venda de livros para uso escolar. Nessa ocasião, a Ática lançou a Série Bom Livro, destinada a disciplina de Língua Portuguesa, composta por obras literárias, "muitas vezes acompanhadas de um suplemento de atividades para o aluno e de outro especialmente organizado para o professor, com todas as respostas prontas, além de orientação metodológica e didática" (FERREIRA; MELO, 2006, p. 196), facilitando o acesso dos estudantes à leitura, por meio de obras e autores diversos. As autoras chamam atenção para o fato de que o objetivo da Ática, naquele momento, era incentivar a leitura e não atender a uma demanda por livros sobre temas específicos de disciplinas do currículo (FERREIRA; MELO, 2006).

Naquela época, os livros didáticos tradicionais, elaborados para atender às disciplinas do currículo, eram objeto de uma política pública que começava a se consolidar - o atual Programa Nacional do Livro Didático (PNLD) - mas havia demanda para obras com conteúdos menos rígidos, que pudessem ser utilizadas complementarmente ao livro didático em diferentes momentos e níveis de ensino. Surgiu assim, a expressão livro paradidático, ou simplesmente paradidático, para designar esse tipo de produção editorial (DALCIN, 2007).

\footnotetext{
${ }^{4}$ A Abrelivros é uma entidade civil, fundada em 1991, que congrega editoras de livros educativos do país. (http://www.abrelivros.org.br/home/)

Bibl. Esc. em R., Ribeirão Preto, v. 6, n. 1, p. 64-80, 2018.
} 


\section{Precursores do paradidático}

Embora o livro paradidático tenha sido assim denominado somente a partir da década de 1970, considera-se que a noção já existisse em alguns livros de Monteiro Lobato, que apresentavam, além de elementos ficcionais, uma intenção pedagógica e utilitarista (DALCIN, 2007). A preocupação de Monteiro Lobato com um ensino divertido e agradável - característica do paradidático - aparece claramente em Emília no país da gramática, publicado pela primeira vez em 1937. O seguinte diálogo de Pedrinho com Dona Benta expõe a crítica do autor aos métodos tradicionais de ensino - nesse caso, a chamada "decoreba" - e revela sua vontade de tornar mais atraente e estimulante o estudo da gramática.

Ah, assim, sim! - dizia ele. - Se meu professor ensinasse como a senhora, a tal gramática até virava brincadeira. Mas o homem obriga a gente a decorar uma porção de definições que ninguém entende. Ditongos, fonemas, gerúndios (MONTEIRO LOBATO, [201-?], p. 5-6).

Percebe-se em vários livros do autor um desejo de superar a concepção tradicional de ensino, ao proporcionar uma maneira prazerosa e agradável de aprender, por meio do texto literário. Emília no país da gramática tem o seguinte trecho onde o personagem do rinoceronte explica diversos conceitos gramaticais para a turma do Sítio do Pica-pau Amarelo, exemplificando essa tendência:

\footnotetext{
Esse país principia justamente ali onde o ar começa a zumbir. Os sons espalhados pelo ar, e que são representados por letras, fundem-se logo adiante em SÍLABAS, e essas Sílabas formam PALAVRAS - as tais palavras que constituem a população da cidade onde vamos. Reparem que entre as letras há cinco que governam todas as outras. São as Senhoras VOGAIS - cinco madamas emproadas e orgulhosíssimas, porque palavra nenhuma pode formar-se sem a presença delas. As demais letras ajudam; por si mesmas nada valem. Essas ajudantes são as CONSOANTES e, como a palavra está dizendo, só soam com uma Vogal adiante ou atrás. Pegue as dezoito Consoantes do alfabeto e procure formar com elas uma palavra. Experimente, Pedrinho (MONTEIRO LOBATO, [201-?], p. 7-8).
}

Assim, Monteiro Lobato, o precursor da literatura infantil no Brasil, é também considerado o precursor do gênero paradidático, juntamente com Júlio Cesar de Mello e Souza, conhecido como Malba Tahan, que buscou tornar palatável e interessante o ensino da tão temida matemática em seu livro $O$ homem que calculava, no qual apresenta problemas e curiosidades matemáticas por meio de narrativas das aventuras de um calculista persa, no estilo das histórias das Mil e uma noites (DALCIN, 2007). 


\section{O desenvolvimento do mercado de paradidáticos}

Como vimos anteriormente, o paradidático surgiu em função do interesse das editoras no incentivo à leitura e consequentemente na ampliação do mercado livreiro. Paralelamente, discussões sobre novas propostas pedagógicas estimulavam as escolas a introduzirem experiências de inovação didática. Para isso, havia necessidade de materiais diferentes, pois professores e pedagogos entendiam que os livros didáticos, muitas vezes produzidos no paradigma do exercício, pouco contribuíam para uma aprendizagem mais crítica e para ampliar e aprofundar conceitos. Assim, os paradidáticos, com sua função complementar, pareciam concorrer para uma aprendizagem inovadora (DALCIN, 2007).

Além disso, outros fatores impulsionaram a produção dos paradidáticos. Em primeiro lugar, políticas públicas, como o PNLD - Programa Nacional do Livro Didático criado em 1937 com outra denominação e o PNBE - Programa Nacional Biblioteca da Escola iniciado em 1998, que abriram possibilidade de aquisição dos chamados textos complementares, um conceito que posteriormente foi sendo consolidado, até que em 2010 o Ministério da Educação implantou o PNLD obras complementares (BRASIL, 2012), estabelecendo com clareza a função dos materiais que, no mercado editorial, recebem a denominação de paradidáticos.

No âmbito do PNBE, o Fundo Nacional de Desenvolvimento da Educação (FNDE) na apresentação do programa em seu site, destaca que o objetivo da distribuição das obras literárias é fornecer a estudantes e professores material de leitura para promoção tanto da "leitura literária como fonte de fruição e reelaboração da realidade, quanto a leitura como instrumento de ampliação de conhecimentos”. Para além disso, no documento Biblioteca na escola editado pelo MEC em 2006, que tem por objetivo discutir com professores e mediadores de leitura o papel da escola na formação de leitores competentes, apresenta-se dentre os tipos de obras a serem disponibilizadas pelas bibliotecas o livro paradidático, sem, contudo, explicitar o conceito desse tipo de material (BRASIL, 2006).

Os Parâmetros Curriculares Nacionais (PCNs) também constituíram um estímulo à produção de paradidáticos ao instituírem os chamados temas transversais, representados por questões que, segundo o documento, devem ser introduzidos nas matérias já existentes na escola (BRASIL, 1997). Os temas transversais sugeridos pelos PCNs foram: Ética, Pluralidade Cultural, Meio Ambiente, Saúde e Orientação Sexual, e foram objeto de inúmeras coleções de paradidáticos. 
Legislações específicas, como a Lei 9.795/1999, que instituiu a Política Nacional de Educação Ambiental (BRASIL, 1999) e a Lei 11.645/2008 que instituiu a inclusão da temática História e Cultura Africana e Afro-Brasileira (BRASIL, 2008) no currículo escolar, também alimentaram a demanda aos paradidáticos, levando à produção mais volumosa de materiais sobre os assuntos cobertos pelas referidas legislações.

A recente publicação da Base Nacional Comum Curricular (BNCC), ocorrida em 2017, não contempla explicitamente o termo paradidático, mas revela em suas entrelinhas a importância deste material para as várias aprendizagens possíveis. Na seção 4.2.1.1 que trata das unidades temáticas, objetos de conhecimento e habilidades para a matemática no Ensino Fundamental, por exemplo, observa-se que o livro configura-se ao lado de outros elementos como ábacos, jogos, calculadoras e softwares, como instrumento essencial para a compreensão e utilização de noções geométricas (BRASIL, 2017). Tal finalidade atribuída ao livro como um material de apoio didático, leva ao entendimento de sua função utilitarista que proporciona, tanto ao professor quanto ao aluno, a inserção no ambiente de leitura e interpretação de textos vinculados a problemas do cotidiano, sejam eles atrelados ao contexto matemático, ou não.

A preocupação com a leitura continua a ser um fator preponderante para a produção de paradidáticos. A leitura é vista agora não como prática exclusiva à disciplina de Língua Portuguesa, mas como uma responsabilidade de todos os educadores da escola, que devem se preocupar com a formação de leitores competentes. Portanto, paradidáticos de diferentes disciplinas trazem possibilidades de inserção do estudante no ambiente de leitura e interpretação de textos e, ao mesmo tempo, de contextualizações que ampliam o entendimento daquela matéria.

Assim, fatores comerciais e pedagógicos contribuem para a produção de paradidáticos e os editores brasileiros têm aproveitado todas essas oportunidades, respondendo com uma variedade de obras que atendem com qualidade as demandas do segmento. 


\section{Uso do termo paradidático pelas editoras}

Observa-se que o uso do termo paradidático não é uma prática unânime entre as editoras.

O Quad. 1 apresenta esquematicamente o uso do termo pelas dezessete editoras pesquisadas.

\section{QUADRO 1 - Uso do termo “paradidático" pelas editoras pesquisadas}

\begin{tabular}{|c|c|}
\hline Editora & Uso do termo paradidático \\
\hline $\begin{array}{l}1 \text { EDIÇÕES ESCALA EDUCACIONAL } \\
\text { http://www.editoradobrasil.com.br/ }\end{array}$ & Não usa o termo paradidático \\
\hline $\begin{array}{l}2 \text { EDITORA AJS } \\
\text { http://www.editoraajs.com.br/ }\end{array}$ & Não usa o termo paradidático \\
\hline $\begin{array}{l}3 \text { GLOBAL EDITORA } \\
\text { http://globaleditora.com.br/ }\end{array}$ & Não usa o termo paradidático \\
\hline $\begin{array}{l}4 \text { IBEP / NACIONAL } \\
\text { http://www.editoraibep.com.br/ }\end{array}$ & Não usa o termo paradidático \\
\hline $\begin{array}{l}5 \text { LEYA EDUCAÇÃO } \\
\text { http://www.leyaeducacao.com/ }\end{array}$ & Não usa o termo paradidático \\
\hline $\begin{array}{l}6 \text { MACMILLAN } \\
\text { http://www.macmillan.com.br/ }\end{array}$ & Não usa o termo paradidático \\
\hline $\begin{array}{l}7 \text { MULTI MARCAS EDITORIAIS/ } \\
\text { EDITORA CONSTRUIR } \\
\text { http://editoraconstruir.com.br/ }\end{array}$ & Não usa o termo paradidático \\
\hline $\begin{array}{l}8 \text { EDITORA MODERNA } \\
\text { http://www.moderna.com.br/pagina- } \\
\text { inicial.htm }\end{array}$ & Não usa o termo paradidático \\
\hline $\begin{array}{l}\text { 9 EDITORA FTD } \\
\text { https://ftd.com.br/ }\end{array}$ & $\begin{array}{l}\text { Não usa o termo paradidático; tem um link para "Apoio } \\
\text { Didático", com livros separados por temas curriculares e } \\
\text { incluindo dicionários. }\end{array}$ \\
\hline $\begin{array}{l}10 \text { SARAIVA EDUCAÇÃO } \\
\text { http://www.editorasaraiva.com.br/ }\end{array}$ & $\begin{array}{l}\text { Não usa o termo paradidático; tem um link para "Apoio } \\
\text { didático" que remete para livros informativos e de ficção. }\end{array}$ \\
\hline $\begin{array}{l}11 \text { EDIÇÕES SM } \\
\text { http://www.edicoessm.com.br/ }\end{array}$ & $\begin{array}{l}\text { Não usa o termo paradidático; tem um link para "Literatura } \\
\text { e informativos". }\end{array}$ \\
\hline $\begin{array}{l}12 \text { EDITORA OPET } \\
\text { http://www.editoraopet.com.br/ }\end{array}$ & $\begin{array}{l}\text { Não usa o termo paradidático; dentro do link "Soluções } \\
\text { educacionais" apresenta a coleção Além da Escola, } \\
\text { formada por livros informativos. }\end{array}$ \\
\hline $\begin{array}{l}13 \text { EDITORA ÁTICA } \\
\text { http://www.aticascipione.com.br/ }\end{array}$ & $\begin{array}{l}\text { A partir da caixa de busca usando-se o termo paradidático, } \\
\text { remete para o setor de "Didáticos" em geral. }\end{array}$ \\
\hline $\begin{array}{l}\text { 14 EDITORA SCIPIONE } \\
\text { http://www.aticascipione.com.br/ }\end{array}$ & $\begin{array}{l}\text { A partir da caixa de busca usando-se o termo paradidático, } \\
\text { remete para o setor de 'Didáticos" em geral. }\end{array}$ \\
\hline $\begin{array}{l}15 \text { EDITORA DO BRASIL } \\
\text { http://www.editoradobrasil.com.br/ }\end{array}$ & $\begin{array}{l}\text { Tem um link para paradidáticos na página inicial do site, } \\
\text { remetendo para "Literatura infantil", "Literatura juvenil", } \\
\text { "Formação de professores", "E-Pubs", "Suplementos" e } \\
\text { para os catálogos da editora. }\end{array}$ \\
\hline $\begin{array}{l}16 \text { EDITORA POSITIVO } \\
\text { http://www.editorapositivo.com.br/ }\end{array}$ & $\begin{array}{l}\text { A partir da caixa de busca usando-se o termo paradidático, } \\
\text { remete para o setor de paradidáticos com livros } \\
\text { informativos de ficção e não ficção. }\end{array}$ \\
\hline $\begin{array}{l}17 \text { REDE SALESIANA BRASIL/ } \\
\text { EDITORA EDEBE } \\
\text { http://loja.edebe.com.br/ }\end{array}$ & $\begin{array}{l}\text { Usa o termo paradidático no texto institucional, definindo- } \\
\text { o e apresentando a proposta da editora para esses materiais } \\
\text { (http://www.salesianos.br/news/edebe-lanca-linha-de- } \\
\text { livros-paradidaticos/). }\end{array}$ \\
\hline
\end{tabular}

Fonte: Elaborado pelos autores 
Verifica-se que, das dezessete editoras, apenas cinco adotam o termo. Destas, três (Ática, Scipione, Editora do Brasil) dão acesso ao termo por meio de caixas de busca e link e remetem para livros didáticos ou para materiais de variados tipos, como dicionários, material para professor, livros didáticos propriamente ditos, ficção. Uma editora (Positivo) explica sucintamente o termo, dizendo que são livros informativos de ficção e não ficção e usando o slogan: "Paradidáticos: livros que dialogam com livros didáticos". A Editora Edebe é a que explicita com mais clareza a natureza do paradidático, explicando que são

\begin{abstract}
textos que trabalhem o lúdico, a pluralidade cultural, a ética e outros valores que possam estimular os pequenos leitores [...] a equipe projeta ampliar a linha de paradidáticos por meio de coleções que contemplem diversas áreas. Serão lançados clássicos da literatura, obras sobre meio ambiente, educação financeira e muitas outras [...] a perspectiva é de trabalhar os paradidáticos de forma integrada com os livros didáticos (SALESIANOS, 2015).
\end{abstract}

Percebe-se que a explicação assume a natureza lúdica do paradidático, sua estrutura em coleções, e a ideia de complementação do livro didático. Mas o levantamento feito nos sites das editoras mostrou uma tendência para o abandono do termo, já que doze das dezessete não o usam, e algumas o substituem pela expressão apoio didático ou pelo termo informativo.

\title{
Uso do termo paradidático em textos acadêmicos
}

Livros paradidáticos tem sido objeto de estudo de pesquisadores que vêm realizando análises desse tipo de produção editorial para entender melhor diversas questões, como por exemplo: O paradidático traz de fato possibilidade de inovação pedagógica? As informações que apresentam são confiáveis? Que critérios orientam sua produção? (ZAMBONI, 1991; MUNAKATA, 1997; XAVIER, 2004; FURLANI, 2005; DALCIN, 2007). Entretanto, para fins da presente análise, interessa-nos verificar como os autores conceituam o paradidático.

A análise desses textos revela que as controvérsias que cercam a identidade dos paradidáticos são visíveis e seu uso confirma a mesma diluição percebida nos sites das editoras. Em um dos primeiros estudos sobre os paradidáticos, publicado em 1991, a autora já mostrava a indefinição prevalente no conceito:

Não há um padrão definido de paradidático e os editores compõem com certa liberdade livros de formatação variada, coloridos e fundamentalmente dotados de temáticas e propostas teórico-metodológicas aparentemente inovadoras. A invenção do novo é cuidada nos mínimos detalhes: tamanho, a forma dos livros, letras, qualidade do papel, variedade de cores, ilustrações (ZAMBONI, 1991, p. 2-3). 
A autora chama atenção para o esforço de se apresentar o paradidático como um material feito sob medida para possibilitar práticas didáticas inovadoras e parece sugerir um olhar crítico a essa suposta inovação.

Em um estudo sobre os paradidáticos de língua portuguesa, Ferreira e Melo (2006) reforçaram a imprecisão com que o termo tem sido usado:

[...] é possível observar que, atualmente, são considerados paradidáticos de Língua Portuguesa uma grande diversidade de obras, como: livros de literatura infantojuvenil; clássicos nacionais e universais (adaptados ou não), acompanhados de fichas de leitura ou de suplementos de atividades, e/ou qualquer livro considerado de leitura extraclasse; e ainda, livros que abordam um conteúdo gramatical específico, em uma fórmula muito parecida com os demais de outras áreas curriculares. É nesta configuração que os paradidáticos de Língua Portuguesa são hoje assim denominados pelas editoras, tanto pelo seu uso (como apoio didático), como pela abordagem de um conteúdo curricular (FERREIRA; MELO, 2006, p. 196-197).

Observa-se que a concepção de paradidático das autoras acima abarca livros de literatura, posição contrária à de Tavares e Rösing (2017) que enfatizam a separação entre livros literários e paradidáticos. Defendendo a utilização de livros literários (especificamente as lendas) para a educação ambiental, as autoras afirmam que:

O que se precisa saber é que textos literários são diferentes de textos paradidáticos e daqueles construídos com o objetivo específico de informar. [...] os livros paradidáticos são produzidos com finalidade prática: ensinar ao leitor um conteúdo específico, podendo este conteúdo ser mais permanente ou apresentar validade já predeterminada. Não se apresentam como livros literários (TAVARES; RÖSING, 2017, p. 130-131).

Assim, é necessário observar de que maneira o termo é utilizado em cada circunstância. Por exemplo, o Prêmio Jabuti, oferecido pela Câmara Brasileira do Livro reúne em uma mesma categoria os livros didáticos e paradidáticos e os define na perspectiva do uso.

10 - DIDÁTICO E PARADIDÁTICO: Livros destinados ao ensino de qualquer componente curricular e/ou área do conhecimento, voltados para utilização em sala de aula ou como complemento didático dos níveis de ensino: Primeira Infância, Fundamental e/ou Médio e/ou Educação de Jovens e Adultos e Superior (PRÊMIO JABUTI, 2017).

Sintetizando, observa-se no meio acadêmico uma tendência de definir o paradidático pelo uso que se faz dele, isto é, complementação do livro didático tradicional, conforme proposto no Glossário Ceale (RANGEL, 2014. Entretanto, como há autores que usam a separação entre paradidáticos informativos e ficcionais, e por isso é conveniente compreender esse aspecto. 


\section{Paradidáticos informativos}

Quando determinado livro paradidático trata de assunto ligado a uma disciplina do currículo escolar, servindo para complementar o livro didático adotado, ele costuma ser chamado de informativo. Por exemplo, um livro sobre espécies em extinção, que discute questões de meio ambiente, pode complementar o livro de Ciências Biológicas utilizado pelo professor em sala de aula. Essa é uma perspectiva informativa ou temática do paradidático e, nessa circunstância, ele é considerado sinônimo de livro informativo (CAMPELLO, 2009).

O Prêmio FNLIJ, oferecido anualmente pela Fundação Nacional do Livro Infantil e Juvenil, tem uma categoria para informativos. Livros premiados nessa categoria incluem Terra de Cabinha: pequeno inventário da vida de meninos e meninas do sertão (premiado em 2017); Malala, a menina que queria ir para a escola (2016); Carmen: a grande pequena notável (2015); Buriti (2014); Bibliotecas do mundo (2013) (FUNDAÇÃO..., 2017). Os temas e gêneros são variados: Terra de Cabinha é um relato sobre o cotidiano de crianças de uma região do Nordeste, escrito por uma jornalista e documentarista; Malala é categorizado pela editora Companhia das Letrinhas como livro-reportagem, Carmen é claramente uma biografia e Labirintos e Bibliotecas do mundo traz a história e descrição de espaços de interesse didático, reforçando a flexibilidade com que o conceito é usado.

Diferentemente do livro didático, o paradidático informativo não segue obrigatoriamente a seriação e a sequência de conteúdos recomendadas nos currículos. Alguns estudiosos veem isso como um aspecto positivo, pois nos paradidáticos, diferentemente dos didáticos, os temas costumam ser apresentados de forma menos fragmentada, possibilitando a relação com outras áreas do conhecimento e o uso de acordo com o perfil das turmas com as quais este material será trabalhado.

Assis e Teixeira (2005), a partir de uma abordagem dialógica, apresentam possibilidades de atividades com livros paradidáticos que não se caracterizam como lineares, pois, a partir de uma referida discussão inicial sobre um tema abordado no texto, podem ser suscitados outros temas inusitados. As autoras destacam que o uso do texto paradidático, com a mediação do educador, pode oportunizar que os alunos explicitem as suas ideias a qualquer momento, denotando a sua não linearidade. 
Do ponto de vista editorial, os paradidáticos informativos são muitas vezes apresentados em coleções, ou seja, um conjunto de volumes que tratam de assuntos da mesma natureza 5 . Exemplo é a coleção Além da Escola da Editora Opet, que aborda os temas educação física, educação ambiental, educação musical, empreendedorismo, educação para o turismo, educação para o trânsito, conhecimento religioso e cidadania (EDITORA OPET, 2017).

Outro exemplo de coleção é a Tempo de Ciências da Editora do Brasil. As coleções de paradidáticos informativos costumam ser acompanhadas de suplementos de atividades para o aluno e para o professor, além de orientação metodológica e didática. Os suplementos dos paradidáticos da Editora do Brasil, por exemplo, apresentam a obra em detalhes, além de sugerir leituras e atividades variadas. Esse material é disponibilizado gratuitamente na página da Editora na internet (EDITORA DO BRASIL, 2017).

\section{Paradidáticos ficcionais}

Além da perspectiva informativa, o livro paradidático é também apresentado na perspectiva ficcional, podendo ser entendido como qualquer livro de ficção considerado de leitura extraclasse. Na perspectiva de algumas editoras, o paradidático ficcional costuma conter elementos pedagógicos, isto é, é um livro de história que pretende ensinar algo, que tem uma finalidade claramente utilitária. O livro Eu tenho um pequeno problema disse o urso exemplifica isso. É de autoria de Heinz Janisch, conceituado escritor austríaco de literatura para crianças e jovens e se preocupa claramente em passar a ideia da importância da amizade (SALAMANDRA, [201-?]).

Essa é uma característica bem visível nos paradidáticos: a preocupação em estimular atitudes e comportamentos esperados de crianças e jovens e ajudá-los a lidar com medos, com a perda de amigos, com a morte, ou a se relacionar com adultos e colegas, dentre muitas outras questões, aproximando-se do gênero autoajuda.

O fato é que a preocupação em ajudar a resolver problemas que hoje muitas crianças e jovens enfrentam, afeta o universo literário e dificulta a avaliação das obras destinadas a esse

\footnotetext{
${ }^{5} \mathrm{Na}$ perspectiva da indústria editorial, a coleção constitui uma estratégia que visa a conquistar e ampliar o público leitor. Os livros de determinada coleção são caracterizados por dispositivos tipográficos e textuais que lhe dão uma identidade própria e lhe conferem uma homogeneidade que define a coleção e que busca familiarizar o leitor com o conjunto dos livros, orientando suas escolhas e garantindo sua fidelidade ao produto.
} 
público. Observa-se que editoras que tradicionalmente se dedicam a publicar literatura infantil, incluem indiscriminadamente em seus catálogos livros com finalidades utilitárias, não escritos por autores literários, mas por especialistas em psicologia e/ou educação. Exemplos são os livros A elefantinha que queria dormir e $O$ coelhinho que queria dormir, do terapeuta sueco Carl-Johan Forssén Ehrlin, publicado pela Companhia das Letrinhas. Nesse caso, a Editora informa claramente o perfil do autor, sua formação como terapeuta e o objetivo do livro:

Esta história, sobre uma mãe coelho com dificuldade de fazer seu filho dormir tem o objetivo de ajudar os pais com a tão sofrida hora do sono. Trazendo um método especial, é um comprovado sonífero em forma de livro (COMPANHIA DAS LETRINHAS, 2015).

\section{Conclusão}

Buscou-se com este trabalho, compreender o conceito de livro paradidático, uma fonte de informação presente especialmente em bibliotecas escolares, oferecendo ao bibliotecário condições para exercer suas práticas de forma mais embasada.

Analisando-se o contexto do surgimento do termo, que se deu no âmbito do mercado editorial, foi possível compreender a necessidade dos editores de inventar um nome que distinguisse especificamente um tipo de material distinto do livro didático tradicional, que atendesse as demandas educacionais da época.

Observou-se que, embora o termo tenha surgido no final da década de 1970, a noção de paradidático já estava presente desde a década de 1930, em obras de Monteiro Lobato.

Diversos fatores influenciaram a produção de paradidáticos, como o estímulo às experiências de inovação didática, políticas públicas relacionadas ao livro e à leitura, além de diretrizes curriculares de âmbito nacional, abrindo possibilidades para a produção de materiais que complementassem os conteúdos dos livros didáticos tradicionais.

A análise do uso do termo por editoras confirmou a ideia de Thomson (2016) de que a definição de paradidáticos está "diluída", não havendo precisão na sua utilização pelas dezessete editoras que compuseram a amostra do presente estudo.

No âmbito acadêmico verificou-se que o termo é usado, mas a imprecisão persiste, havendo discordâncias marcantes entre autores. Não há consenso entre estudiosos se o livro paradidático constitui um gênero discursivo. A variabilidade de materiais incluídos nessa categoria dificulta a definição de suas características comuns (RANGEL, 2014.). Apesar da 
falta de consenso, pode-se perceber uma preocupação em compreender o uso que se faz desse material na escola, o que implica entender como professores complementam os livros didáticos tradicionais.

A constatação de que no âmbito do mercado editorial o termo tem sido pouco usado e que nos documentos de políticas públicas ele não aparece, pode indicar que o termo está perdendo força nesses contextos.

Considera-se que o bibliotecário deva estar a par das diferentes fontes com que trabalha, mas no que diz respeito às suas práticas, o foco seria no domínio das diretrizes curriculares locais e nacionais e no conhecimento das necessidades informacionais de professores e alunos para subsidiar uma avaliação criteriosa dos materiais passíveis de supri-las, mais do que prender-se a definições e tipologias rígidas desses materiais. O bibliotecário deve acompanhar os lançamentos, escolher os melhores para formar uma coleção adequada e apoiar os professores e estudantes no seu uso.

\section{Referências}

BRASIL. Ministério da Educação. Base Nacional Comum Curricular. Brasília: MEC, 2017. Disponível em: 〈http://basenacionalcomum.mec.gov.br/images/BNCC_20dez_site.pdf $>$. Acesso em: 10 jan. 2018.

BRASIL. Congresso Nacional. Lei $n^{\circ} 11.645$ de 10 março de 2008. Altera a Lei $n^{\circ} 9.394$, de 20 de dezembro de 1996, modificada pela Lei $\mathrm{n}^{0}$ 10.639, de 9 de janeiro de 2003, que estabelece as diretrizes e bases da educação nacional, para incluir no currículo oficial da rede de ensino a obrigatoriedade da temática "História e Cultura Afro-Brasileira e Indígena".

Diário oficial da União, 11 mar. 2008. Disponível em: <http://www.planalto.gov.br/ccivil_03/_ato2007-2010/2008/lei/111645.htm>. Acesso em: 20 mar. 2017.

BRASIL. Ministério da Educação, Secretaria de Educação Básica. Acervos complementares: as áreas do conhecimento nos dois primeiros anos do Ensino Fundamental. Brasília: MEC/SEB, 2012. Disponível em:

$<$ http://portal.mec.gov.br/index.php?option=com_docman\&view=download\&alias=12696acervoscomplementares-2013-site-pdf\&Itemid=30192 > . Acesso em: 10 abr. 2017.

BRASIL. Ministério da Educação, Secretaria de Educação Básica. Biblioteca na escola. Brasília: MEC/SEB, 2006. Disponível em:

$<$ http://portal.mec.gov.br/index.php?option=com docman\&view=download\&alias=7260biblioteca-escola-seb\&category_slug=dezembro-2010-pdf\&Itemid=30192> . Acesso em: 13 jan. 2018. 
BRASIL. Secretaria de Educação Fundamental. Parâmetros Curriculares Nacionais: apresentação dos temas transversais, ética. Brasília: MEC/SEF, 1997. Disponível em: <http://portal.mec.gov.br/seb/arquivos/pdf/livro081.pdf>. Acesso em: 15 mar. 2017.

CAMPELLO, B. S. Leitura informativa. In: Letramento informacional: função educativa do bibliotecário na escola. Belo Horizonte: Autêntica, 2009. Cap. 7, p. 71-78.

CAMPELLO, B. S.; CALDEIRA, P. T. (Org.). Introdução às fontes de informação. Belo Horizonte: Autêntica, 2005. 181 p.

CAMPELLO, B. S.; CALDEIRA, P. T.; MACEDO, V. A. A. (Org.). Formas e expressões do conhecimento: introdução às fontes de informação. Belo Horizonte: Escola de Biblioteconomia da UFMG, 1998. 414 p.

CAMPELLO, B. S.; CENDÒN, B. V.; KREMER, J. M. (Org.). Fontes de informação para pesquisadores e profissionais. Belo Horizonte: Editora UFMG, 2000.

COMPANHIA DAS LETRINHAS. O coelhinho que queria dormir. São Paulo. [2015?]. Disponível em: <https://www.companhiadasletras.com.br/detalhe.php?codigo=41189>. Acesso em: 30 ago. 2017.

CUNHA, M. B. Manual de fontes de informação. Brasília: Briquet de Lemos, 2010.

EDITORA DO BRASIL. Suplementos. São Paulo, 2017. Disponível em:

<http://editoradobrasil.com.br/literatura/suplementos>. Acesso em: 06 abr. 2017.

EDITORA OPET. Coleção Além da Escola. 2017. Disponível em:

<http://www.editoraopet.com.br/solucoes-educacionais/materiais-paradidaticos/>. Acesso em: 12 set. 2017.

EDITORA POSITIVO. Tem pena ou tem pelos? Curitiba. [201-?]. Disponível em: <https://loja.editorapositivo.com.br/paradidaticos/tem-penas-ou-tem-pelos/1176-tem-penasou-tem-pelos >. Acesso em: 21 nov. 2017.

MONTEIRO LOBATO, J. B. Emília no país da gramática. São Paulo: Círculo do Livro, [201-?]. Disponível em:

$<$ http://www.miniweb.com.br/cantinho/infantil/38/Estorias_miniweb/lobato/Emilia_No_Pais Da_Gramatica.pdf $>$. Acesso em: 17 abr. 2017.

FUNDAÇÃO NACIONAL DO LIVRO INFANTIL E JUVENIL. Prêmio FNLIJ. Rio de Janeiro: FNLIJ, 2017. Disponível em: 〈http://www.fnlij.org.br/site/premio-fnlij.html>. Acesso em: 17 abr. 2017.

PRÊMIO JABUTI. Câmara Brasileira do Livro. Categorias. 2017. Disponível em <http://premiojabuti.com.br/categorias/>. Acesso em: 17 abr. 2017.

SALAMANDRA. Destaques. São Paulo. c2013. Disponível em:

<http://www.salamandra.com.br/pagina-inicial-3.htm>. Acesso em: 21 nov. 2017. 
SALESIANOS/ INSPETORIA SÃO JOÃO BOSCO. Edebe lança linha de livros

paradidáticos. Belo Horizonte, 2015. Disponível em: <http://www.salesianos.br/news/edebelanca-linha-de-livros-paradidaticos/>. Acesso em: 21 nov. 2017.

SILVEIRA, F. J. N. Biblioteca como lugar de práticas culturais: uma discussão a partir dos currículos de Biblioteconomia no Brasil. 2007. Dissertação (Mestrado em Ciência da Informação) - Escola de Ciência da Informação, UFMG, Belo Horizonte, 2007.

TOMAEL, M. I.; ALCARÁ, A. R. (Org.). Fontes de informação digital. Londrina: Eduel, 2016.

\section{APÊNDICE Textos utilizados na análise}

ASSIS, A.; TEIXEIRA, O. P. B. Análise de um episódio de ensino envolvendo o uso de um texto paradidático em aulas de Física em uma sala de educação de jovens e adultos. In: ENCONTRO NACIONAL DE PESQUISA EM EDUCAÇÃ̃O EM CIÊNCIAS, 5., 2005, Bauru. Atas... Bauru: Abrapec, 2005. Disponível em:

$<$ http://abrapecnet.org.br/atas_enpec/venpec/conteudo/artigos/3/pdf/p45.pdf $>$. Acesso em: 02 mai. 2012.

DALCIN, A. Um olhar sobre o paradidático de Matemática. Zetetiké, Campinas, v. 15, n. 27 , p. 25-36, jan./jun. 2007. Disponível em:

<http://ojs.fe.unicamp.br/ged/zetetike/article/view/2418/2180>. Acesso em: 16 fev. 2017.

FERREIRA, N. S. A.; MELO, E. A. A. Livros paradidáticos de língua portuguesa: a nova fórmula do velho. Pro-Posições, Campinas, v. 17, n. 2, p. 195-209, mai./ago. 2006.

Disponível em: 〈http://www.proposicoes.fe.unicamp.br/proposicoes/edicoes/texto66.html >. Acesso em: 06 abr. 2017.

FURLANI, J. O bicho vai pegar: um olhar pós-estruturalista à educação sexual a partir dos livros paradidáticos infantis. 2005. Tese - (Doutorado em Educação). Programa de PósGraduação em Educação, Faculdade de Educação, Universidade Federal do Rio Grande do Sul, Porto Alegre, 2005. Disponível em: <http://www.lume.ufrgs.br/handle/10183/13259>. Acesso em: 16 fev. 2017.

MUNAKATA, K. Produzindo livros didáticos e paradidáticos. 1997. 223 f. Tese (Doutorado em Educação). Programa de Estudos Pós-Graduados em Educação, Pontifícia Universidade Católica de São Paulo, São Paulo, 1997.

RANGEL, E. O. Paradidáticos. In: UFMG. FAE. Glossário Ceale: termos de alfabetização, leitura e escrita para educadores. Belo Horizonte: CEALE/Faculdade de Educação da UFMG, [2014]. Disponível em:

<http://ceale.fae.ufmg.br/app/webroot/glossarioceale/verbetes/paradidaticos >. Acesso em: 18 abr. 2017.

TAVARES, M. C.; RÖSING, T. M. K. Do literário ao paradidático: textos para crianças em meio a crises ambientais. Textura, Canoas, v. 19, n. 39, p. 112-133, jan./abr. 2017. 
THOMSON, A. B. A. Os paradidáticos no ensino de História: uma reflexão sobre a literatura infantil/juvenil na atualidade. Revista do Lhiste, Porto Alegre, v.3, n. 4, p. 27-49, jan/jun. 2016.

XAVIER, M. E. R.; KERR, A. S. A análise do efeito estufa em textos paradidáticos e periódicos jornalísticos. Caderno Brasileiro de Ensino de Física, Florianópolis, v. 21, n. 3, p. 325-349, dez. 2004.

ZAMBONI, E. Que história é essa?: uma proposta analítica dos livros paradidáticos de História. 1991. Tese - (Doutorado em Educação). Programa de Pós-Graduação em Educação, Faculdade de Educação, Universidade Estadual de Campinas, Campinas, 1991. Disponível em: <http://repositorio.unicamp.br/handle/REPOSIP/251903 >. Acesso em: 16 fev. 2017. 